\title{
Mental Accounting in Managers' Preferences Related to Aggregation Versus Disaggregation Income Statement Items
}

\author{
Shanti* \\ Widya Mandala Catholic University, Dinoyo Street 42-44, 60265, Surabaya, Indonesia \\ Student of Doctoral Program at Airlangga University, Airlangga Street 4-6, 60286, Surabaya, Indonesia
}

\begin{abstract}
Objective - The objective of this study is to observe the mental accounting of managers when choosing between aggregate or disaggregate items in income statements. Managers who experience mental accounting may behave opportunistically because they may consider cost-benefits based on which of the two has a higher utility.

Methodology/Technique - This study is experimental in design. It involves 40 accounting graduates who have been working for at least three years in the same company as decision makers in the field of finance and accounting.

Findings - The test results of the research experiment using MANOVA Test (Factorial Design) with SPSS 23 found that overall, the managers will support the presentation of aggregate or disaggregate based on which one of the two has a higher utility. Therefore, managers' preferences related to items of gains and losses in the income statement are consistent with mental accounting.
\end{abstract}

Novelty - The outcome of this study could be used to explain how the parties involved in external financial reporting and voluntary disclosure behave in accordance with the principles of the theory of mental accounting.

Type of Paper: Empirical

Keywords: Mental Accounting; Aggregation; Disaggregation; Gain; Loss.

JEL Classification: M21, M41.

\section{Introduction}

Guidelines for financial reporting today provides managers with the flexibility to choose whether to merge (aggregation) or separate (disaggregation) items in the income statements. Such a flexibility could become problematic if managers choose to combine (aggregation) in some situations and separate (disaggregation) in other situations, based on the need to make beneficial representations of companies in looking gainable. Previous studies (McVay, 2006; Lansford et al., 2013; Bonner et al., 2014) have showed that managers have a preference to decide on how the information should be presented in the financial statements or voluntary disclosures. This can occur even when holding a constant main economic number such as net income that is related to the value. Due to this, it can thus be said that accounting standard setters do not have an agreed

\footnotetext{
* Paper Info: Received: September 14, 2016

Accepted: December 17, 2016

* Corresponding author:

E-mail: shanti1794@gmail.com

Affiliation: Widya Mandala Catholic University, Indonesia
} 
conceptual approach towards aggregation versus disaggregation. When this discrepancy occurs, managers of respective companies can exploit inconsistencies or flexibility in the financial reporting guidelines so as to achieve a more favorable financial reporting (White, et al., 2003). According to Healy and Wahlen (1999), when managers use considerations (judgments) in their financial reporting and in structuring transactions which alter the financial reporting appearance, either to mislead some stakeholders about matters underlying the performance of economic companies or to influence contractual outcomes that depend on accounting numbers reported, it is the time when earning management occurs.

There are several ways to manage earnings. Among these are: 1) Managing gains between reporting periods (sometimes called management of accruals) (Burgstahler and Dichev, 1997; Schrand and Walther, 2000), and 2) Managing the classification of items in the income statement (McVay, 2006; Fennema and Koonce, 2010). In this regard, the theory of mental accounting can be applied to both types of earnings management. In reporting and presenting items in the income statement, the theory of mental accounting can be used to predict managers' preferences in lieu of aggregation versus disaggregation. The theory of mental accounting contains three main features (i.e. coding, categorizing, and evaluating) which are aligned with important features of financial reporting and voluntary disclosure. Mental accounting may thus act as the moderator by potentially changing the encoding and evaluation related to line items in the income statement. According to Fennema and Koonce (2010), although the theory of mental accounting was developed for decision making consumers and households, the idea can also be applied to providers and external users of financial reporting and voluntary disclosure. This provides a parallelization between mental accounting and financial reporting. As an example, the presenter of financial statements regularly provided the code and the accruals of cash flow as gains and losses. This is then categorized into commonly used classifications such as recurring or transient, before being evaluated periodically. Because of this, it seems reasonable that the presenters and users of financial reporting would also use mental accounting as a preference for indicating gains and losses of items in the income statement.

The current study sets out to complement and add to previous studies by observing the mental accounting of managers in choosing whether to aggregate or disaggregate items in the income statement. In other words, this study aims to see whether the preference of aggregation versus disaggregation of managers will vary systematically, depending on the signs (gain or loss) and the relative magnitudes of the items in the income statement. Finally, this study aims to see whether managers are consistent in their preferences of mental accounting.

Just as companies have a certain accounting system in their organization, managers also possess a certain mental accounting system of their own. It is assumed that managers who have mental accounting may possess opportunistic behavior by taking decisions based on cost-benefit considerations related to higher utility values. The research question this study aims to answer is " Does the preference of aggregation versus disaggregation of managers vary systematically, depending on the signs (gains or losses) and the relative magnitudes of the items in income statement? (Or whether the manager will be consistent with the preferences of mental accounting?).

This study will contribute to existing literature by raising awareness for managers, investors, creditors, financial accounting standard setters' regulators, and researchers on the existence of opportunistic behavior of managers in the decision-making process that is related to aggregation versus disaggregation items in the income statement, in terms of gains and losses.

\section{Literature Review and Hypotheses}

\subsection{Mental Accounting}

Mental accounting was propounded and developed by Professor Richard Thaler (1985) who was from Chicago University. In itself, mental accounting can be interpreted as a series of cognitive measures of economic actors in managing, evaluating and maintaining financial activities (Thaler, 1999). From another 
perspective, mental accounting is the activity of coding, categorizing, and evaluating financial decisions (Pompian, 2006). In his assertion, Thaler (1999) claims that mental accounting includes three main components. The first component relates to how an outcome is perceived and used as an experience. It also looks at how to make decisions and then evaluating those decision (referred to as encoding). The second component involves the activity of elaborating a detailed account, for example, to group the sources and to label the use of funds properly (known as categorization). The last component includes the frequency an account is evaluated. The more frequently an account is evaluated, the more careful the person will be in taking subsequent decisions (known as evaluation). The account evaluated will then be rebalanced periodically.

Thaler (1990) and Davis (2003) found that mental accounting allows the transaction to be evaluated separately from other transactions. This will reduce the cognitive burden of decision-making thus, easing the decision-making process. The theory of mental accounting refers to some fundamental ideas of the prospect theory developed by Kahneman and Tversky (1979). The prospect theory describes how individuals decide between alternatives that involve risks. Here, the risk is viewed as a gain or loss rather than as the end result of wealth or well-being. The prospect theory is related to decisions that produce single unitary outcomes whereas the mental accounting theory is related to the results involving two or more different events. Thus, the fundamental issue noted in mental accounting is whether some of the results are combined (aggregation) before being subjected to the prospect theory value function, or, if they should be evaluated separately (disaggregation) in the context of value function and if so, should they then be combined (aggregation)? This distinction is important. An example illustrating this is provided below.

If an art collector bought a famous painting for \$ 1 million and then sold it for \$ 3 million, the value received from the two transactions would depend on whether they were viewed as one mental account (i.e. net gain of $\$ 2$ million) or as two separate accounts (i.e. a loss of $\$ 1$ million and $\$ 3$ million gain). Mental accounting is based on three key ideas/principles, namely: (1) Encoding, (2) Categorization, and (3) Evaluating (Thaler, 1999; Fennema and Koonce, 2010). Encoding captures the process of how financial results are received and experienced. In a large part, encoding involves determining how individuals assess the number of results of inflow or outflows under consideration (namely, how they are aggregated/combined or disaggregated/separated) and their marks (i.e. gain or loss). Categorization involves the placement of inflows or outflows to certain mental accounts such as investment account or holiday account. The last component is evaluation which is concerned with how the accounts are evaluated after they were coded and categorized. This process also includes taking into consideration the frequency at which mental accounts are evaluated (eg, daily, monthly, or yearly). Each of these components affect how people make financial decisions.

\subsubsection{Mental Accounting - Role of Encoding, Categorization, and Evaluation}

The fundamental ideas in the encoding process behind mental accounting are described below. First, an individual encodes (or parse) an event into two or more results (outcomes). The principles used to do the coding is referred to as hedonic editing where people combine or separate some results so as to achieve the highest perceived value in prospect theory value function. According to Thaler (1985), Thaler and Johnson (1990), in particular, individuals who have a utility function in S-shaped of prospect theory would tend to do the following:

-Separate Gain - For example, it is better to win a lottery for $\$ 50$ and $\$ 25$ lottery than winning a lottery for $\$ 75$.

-Combine Loss - For example, a debt of \$ 150 notice from the IRS with respect to an error is better than one debt notice from the IRS for $\$ 100$ and the other from the state income tax authority of $\$ 50$.

- Cancel Loss Against Bigger Gain - Since the function of loss is steeper than gain function, then the cancellation of loss against greater gains have more utility than gain or loss and separately evaluated and then combined. 
-Separate Large Loss and Small Gain - The waning utilities (diminishing utility) for the loss means that a small gain would not increase more value if the gain and loss are combined. If separated, then gain can be considered as "silver lining."

The principle of hedonic editing has been proven to be valid descriptively with one exception (Thaler, 1985; Thaler and Johnson, 1990). This exception is related to the case of loss experienced many times. There are individuals who tend to want to spread the loss over time. Mental accounting theory would therefore, suggest that losses experienced many times should be combined (aggregation) because of the diminishing sensitivity of function loss. In other words, the marginal impact of any additional loss of $\$ 1$ is smaller than if the loss is separated. Second, people tend to encode transactions and events not only in terms of actual dollars involved but also in terms of whether the transaction and event are seen as good or bad. The final evaluation brings additional gains and losses especially with arithmetic mental accounting. Thus, whether something is a good agreement (referred to as utility transaction) depends on the point of reference adopted by decision makers. Mental accounting is related to the role of categorization which acknowledges that the decision made is quite different, depending on which category of funding streams is encoded. Mental accounting related to the role of the evaluation shows that the type of account in which the original transaction is placed affects the subsequent evaluation (and often behavior). Mental accounting also addresses how often people evaluate their mental account (and how often they will shut it down).

\subsection{Mental Accounting - Aggregation Versus Disaggregation}

According to Bonner et al. (2014), the prospect theory discusses the evaluation of the results such as the individual's reaction to a gain of $\$ 500$ whereas mental accounting focuses on some of the results. Mental accounting discusses issues such as whether people prefer to combine a gain of $\$ 500$ and $\$ 400$ of income into one mental account or to consider them as two separate accounts. This is important as a matter of choice because changes in the (value) of individual utility will be different depending on whether the two events were evaluated separately (i.e., $v(x)+v(y)$ ), or combined and then evaluated (i.e., $v(x+y))$. In the case of the income statement, people will compare the utility of one line of item that combines gains and/or losses for the combined utility of the line items that separate gain and/or loss. Based on the value curve of prospect theory, mental accounting theory predicts that people will prefer to aggregate an overall loss comprising of several smaller losses. Convexity of the value function in the domain of losses leading to the disutility of combining loss is less than the total disutility of several individual losses. Conversely, individuals will prefer to separate (disaggregate) an overall gain of a few gains because concavity of the value function on gain. The total utility of a few individual gains will exceed the utility derived from combining (aggregate) individual gains into a larger gain. Turning to the mix of gains and losses, mental accounting theory predicts that people will prefer to aggregate combined gains and losses (aggregate) to form an overall gain. Due to the steep slope of the value function in the domain of loss, the disutility of separation (disaggregate) showed a greater loss than the positive utility added, that comes from showing greater gains. Conversely, when the gain and loss combine to form the overall loss, predictions of the theory of mental accounting depend on the size of the underlying gain and loss. When the overall loss is composed of a big loss and a relatively small gain, it is often called "loss with a silver lining". When this happens, individuals would prefer to disaggregate. However, as discussed by Thaler (1985, 1999), as a measure of gain increases relative to the size of the loss, the preference for reporting aggregate or disaggregate is sensitive to the specific form of the value function of the individual (Abdellaoui et al., 2007). Hence, it is difficult to make predictions in-median of prediction in this setting. Consequently, researchers do not make a prediction in terms of directions for a small net loss situations (Linville and Fischer, 1991). Therefore, drawing on the curve value of the S-shaped of prospect theory, mental accounting theory would show that the preference of aggregation or disaggregation, depends on the items of gain or loss and their relative magnitudes. In short, mental accounting states that if the utility of combining (aggregation) two or more items exceeds their disaggregation, then people will prefer to combine (aggregation) these items into one "mental 
account" (the aggregate of these items in the income statement). Otherwise, they would prefer to keep the items in the mental accounts separately (separates/disaggregation of the items in the income statement). Overall, managers will support the presentation of aggregate or disaggregate based on which one of the two has a higher utility. Bonner et al. (2011) state company managers may be inclined towards making decisions about sorting (disaggregation) in order to achieve the desired results of reporting. Bonner et al. (2014) assert that managers' preferences are consistent with mental accounting. Based on the above literature review, the research hypothesis is:

Ha: Preference of aggregation versus disaggregation of managers will vary systematically depending on the sign (gains or losses) and the relative magnitudes of the items in the income statement (or that managers' preference will be consistent with mental accounting).

\section{Methods}

This research is quantitative in nature. It uses the research method of experiments involving 40 graduates who have been working for at least three years in the same company as decision makers in the field of accounting and finance. This research takes on the view that even though the participants were not actual managers, they could serve as proper surrogates for decision-making related to preference of aggregation versus disaggregation of items in the income statement. The experimental design used is similar to the research design applied by Bonner et al. (2014), i.e. a $2 \times 2$ factorial design where the conditions (within-subject) namely, gain and loss were crossed with presentation (between-subject) by aggregation or disaggregation. The instrument of this study was placed in two scenarios. First the scenario of experiments related to gains and losses were presented in an integrated manner (aggregation). Next, the scenarios of experiment related to gains and losses were presented separately (disaggregation). The test results noted from this research experiment uses the MANOVA Test (Factorial Design) with SPSS 23. In the context of this study, mental accounting in itself is defined as a set of cognitive operations used by individuals to give a code of financial activities as gains and losses, to then categorize the code items into various mental accounts before evaluating them (Thaler, 1999). Since the theory of mental accounting had expanded from the prospect theory through a deal with a wide range of outcomes (multiple outcomes), the fundamental issues noted in mental accounting include:

a. whether multiple outcomes are combined (aggregation) before becoming subject to value function or

b. whether they are evaluated separately (disaggregation) in the context of value function and then combined (aggregation).

Other important features noted include the categorization of mental accounting. This encompasses the placement of gains and losses in a particular mental account such as account investment or consumption. This type of account showing gains and losses is very much placed in mental accounting because it can influence the subsequent behavior of managers including the mental frequency by which the accounts are evaluated (eg, daily, monthly, or yearly) and how the subsequent expenditure was coded and evaluated. Aggregation is presenting the components underlying one or more items in the financial statements combined. Disaggregation is presenting the underlying component of one or more items in the financial statements separately. For example, it helps managers to decide whether the financial instrument is debt or equity and whether the sale of the business is discontinued operations or not.

\section{Results and Findings}

Table 1 presents the test results of MANOVA (Factorial Design) with SPSS 23. 
Table 1. Statistic Descriptive (Means)

\begin{tabular}{|l|c|c|}
\hline & \multicolumn{2}{|c|}{ Presentation } \\
\hline Condition & Aggregation & Disaggregation \\
\hline Gain & 52.25 & 81.00 \\
\hline Loss & 85.00 & 47.25 \\
\hline Large Gain and Small Loss & 85.00 & 65.50 \\
\hline Small Gain and Large Loss & 60.25 & 81.00 \\
\hline Large Gain and Large Loss & 80.00 & 79.50 \\
\hline Small Gain and Small Loss & 85.00 & 81.00 \\
\hline
\end{tabular}

The statistic descriptions provided in Table 1 above show that when conditions are gainable, people tend to have a preference for separating (disaggregation) the gain. In this regard, the gains that occur would seem to be a lot. From the result, it seems as though the mean of the disaggregation (81.00) is larger than the mean of aggregation (52.25). Conversely, at a loss, individuals tend to have a preference to combine (aggregation) losses so that the loss is seen only through one item. Due to this, it appears as though the mean of aggregation (85.00) is greater than the mean of disaggregation (47.25). In the condition where there are two events, namely the large gain and small loss, people tend to have a preference for combining (aggregation) large gain and small loss into one that would still be in the gainable perspective with the loss condition being not visible. Thus, it appears as though the mean of the aggregation (85.00) is greater than the mean of the disaggregation (65.50). However, in the condition where there are two events, namely a small gain and large loss, people tend to have the preference to separate (disaggregation) the small gain from the large loss so that it would still seem gainable, albeit in small quantities. Thus, it would appear as if the mean of disaggregation (81.00) is greater than the mean of aggregation (60.25). Under the condition where both gain and loss are large and small respectively, people tendency to have a preference for combining (aggregation) and/or separating (disaggregation) both gain and loss is not much different. This suggests that in a state of large gain and large loss or small gain and small loss, people are equally likely to have the preference to combine (aggregation) and separate (disaggregation) the gain and loss.

Table 2. MANOVA (Factorial Design)

\begin{tabular}{|l|c|c|}
\hline & Statistic & Sig. (p-value)* \\
\hline Presentation & $\mathrm{F}=6.181$ & 0.022 \\
\hline Condition & $\mathrm{F}=0.016$ & 0.030 \\
\hline Presentation x Condition & $\mathrm{F}=78.691$ & 0.000 \\
\hline
\end{tabular}

$* 95 \%$ Confidence Interval $(\alpha=5 \%)$

From the result noted of the MANOVA (Factorial Design), it appears that the presentation (a between participants' variable) and condition (a within-participants variable) affected the reporting preferences of the participants (Sig. 0,000). In this regard, the mental accounting theory had suggested that the preference to apply aggregation or disaggregation, depends on whether the items are in gain or loss and their relative magnitudes. In the context of this study, it appears that if the utility of combining (aggregation) two or more items exceeds disaggregation, then people tend to prefer to combine (aggregation) the items into one "mental account" (aggregate the items in the income statement). Otherwise, people would prefer to keep the code items in the mental account separately (separates/disaggregate the items in the income statement). Overall, the managers tend to support the presentation of aggregate or disaggregate based on which one of these has a higher utility. Therefore, the hypothesis (Ha) formulated in this study which says that the preference of managers is consistent with mental accounting, is supported. Consistent with Bonner et al., (2014), the results of this study further indicate that the preference of aggregation versus disaggregation of managers will vary systematically 
depending on the sign (gains or losses) and the relative magnitudes of the items in the income statement or the preferences are consistent with mental accounting.

\section{Discussion}

Flexibility for managers to choose whether to combine (aggregation) or separate (disaggregate) items in the income statement, is based on the presentation of the financial reporting. This is applied by managers when they want to make the company seem more gainable. The reason is because investors who evaluate the economic outlook of a company will be influenced by the company's performance and the information projected through the aggregate or disaggregate models. From what has been examined in this study, it appears that the existence of mental accounting in managers' preference of aggregation versus disaggregation is related to the items presented in the income statement. The expectation of this study is to provide additional information which shows how mental accounting influence the projection of a company's financial reporting statement as this domain is still new. By identifying whether there could be other factors which are more basic/fundamental in the form of pins (gain versus loss), it can be seen that whether managers present the results (outcomes) in the aggregate or disaggregate. In other words, mental accounting is a strong theory that can be applied to financial reporting because it allows researchers to make predictions on a wide range of income statement items. Furthermore, the outcome of this study enables researchers to understand previous findings. This study supports what Riedl and Srinivasan (2010) found, that companies were more likely to separate (disaggregate) special items when their aggregate effect is to produce a net loss rather than a net gain.

\section{Conclusion, Implications, and Significance}

The theory of mental accounting applied in this study has proven to be important for making financial decisions as seen in the results (outcomes) which illustrate how financial items are coded, categorized and evaluated. The three main features of the theory of mental accounting (i.e. coding, categorizing, and evaluating) is in line with important features noted in financial reporting and voluntary disclosure. For example, the presenter's financial statements (managers) are regularly encoded and categorized as transactions. They are then evaluated. From this process, it seems reasonable to deduce that the renderer and financial reporting users will use mental accounting. The results had also shown that managers' preferences are consistent with mental accounting. Managers' preference to aggregate versus disaggregate will vary systematically, depending on the sign (gains or losses) and the relative magnitudes of the items in the income statement. Contributions of this research are expected to create a higher awareness among managers, investors, creditors, financial accounting standard setters, regulators, and researchers on the opportunistic behavior of managers in the decision-making process. The implication of this research is that managers' preferences reflects mental accounting. According to Fennema and Koonce (2010), although there are similarities between the ideas in mental accounting and the domain of financial reporting and voluntary disclosure, only a few studies have relied on the theory of mental accounting to examine the issues in accounting. Therefore, the theory of mental accounting is important because it can provide new insights for researchers who are interested in studying topics related to financial reporting and voluntary disclosure. For example, the theory of mental accounting may indicate that the effects of gainable results with regard to manager disaggregate may be tempered by the type of line item details that emerge from the disaggregation. Hence, by referring to the theory of mental accounting, it can be seen that disaggregation reveals a number of positive sources of income (for example, revenues and gains) and this could be better than revealing sources that tend to be negative than earnings (eg, expenses and losses), even though the amount of gain in bottom-line is constant.

\section{References}

Abdellaoui, M., Bleichrodt, H., \& Paraschiv, C. (2007). Loss aversion under prospect theory: a parameter free measurement. Management Science, 53 (10), 1659-1674. 
Bonner, S., Clor-Proell, S., Koonce, L., \& Wang, T. (2011). Compound financial instruments: is the whole equal to the sum of the parts? Working Papers.

Bonner, S., Clor-Proell, S., \& Koonce, L. (2014). Mental accounting and disaggregation based on the sign and relative magnitude of income statement items. The Accounting Review, 89(6), 2087-2114.

Burgstahler, D. \& Dichev, L. (1997). Earnings management to avoid earnings decreases and losses. Journal of Accounting and Economics, 24(1), 99-126.

Davis, A. (2003). The value relevance of revenue for internet firms: does reported grossed-up and barter revenue make a difference? Journal of Accounting Research, 40 (2), 445-477.

Fennema, M. G. \& Koonce, L. (2010). Mental accounting in financial reporting and voluntary disclosure. Journal of Accounting Literature, 29, 1-29.

Healy, P. M. \& Wahlen, J. M. (1999). A review of the earnings management literature and its implications for standard setting. Accounting Horizons, 13(4), 365-383.

Kahneman, D. \& Tversky, A. (1979). Prospect theory: an analysis of decision under risk. Econometrica, 47 (2), $263-291$.

Lansford, B., Lev, B., \& Wu Tucker, J. (2013). Causes and consequences of disaggregating earnings guidance. Journal of Business Finance \& Accounting, 40(1-2), 26-54.

Linville, P. \& Fischer, G. (1991). Preferences for separating or combining events. Journal of Personality and Social Psychology, 60(1), 5-23.

McVay, S. E. (2006). Earnings management using classification shifting: an examination of core earnings and special items. The Accounting Review, 81(3), 501-531.

Riedl, E. \& Srinivasan, S. (2010). Signalling firm performance through financial statement presentation: an analysis using special items. Contemporary Accounting Research, 27(1), 289-332.

Schrand, C. \& Walther, B. (2000). Strategic benchmarks in earnings announcements: the selective disclosure of priorperiod earnings components. Accounting Review, 75(2), 151-177.

Thaler, R. H. (1985). Mental accounting and consumer choice. Marketing Science, 4 (3), 199-216.

Thaler, R. H. (1990). Saving, fungibility and mental accounts. Journal of Economic Perspectives, 4, $193-205$.

Thaler, R. H. (1990). Anomalies: saving, fungibility, and mental accounts. Journal of Economic Perspectives, 4 (1), $193-$ 205.

Thaler, R. H. (1999). Mental accounting matters. Journal of Behavioral Decision Making, 12 (3), 183-206.

Thaler, R. H. \& Johnson, E.J. (1990). Gambling with the house money and trying to break-event: the effects of prior outcomes on risky choice. Management Science, 36, 643-660.

White, G. I., Sondhi, A. C., \& Fried, D. (2003). The analysis and use of financial statements (Vol. 1). John Wiley \& Sons. 